\title{
An Analysis of the Equal Freedom
}

\author{
Andrzej Stoiński \\ University of Warmia and Mazury \\ in Olsztyn, Poland \\ e-mail: andrzej.stoinski@gmail.com
}

\begin{abstract}
:
The article concerns selected problems related to the postulates of equalizing the level of positive liberty. The classic understanding of individual freedom, called as negative (freedom from), identified with a lack of compulsion, can be in opposition to the so-called positive liberty (freedom to). The last notion is generally defined by an ability, which brings its relation with a concept of power. The postulate of equality in "freedom to" can be justification for conducting a social redistribution of goods. The cases of voluntary and compulsory donation are considered in the text, whose aim is to visualize consequences resulting from a compulsory expansion of the scope of positive liberty.

Keywords: political philosophy, ethics, freedom, positive liberty, negative liberty.
\end{abstract}

\section{Introduction}

Freedom occurs in various contexts. We can consider political, economic liberty and freedom of speech, freedom of the will, etc. However, in this text, we will concentrate our attention to liberty called as an individual. We will deal with a problem, which can occur in a case when a postulate of popularising an equality of positive liberty is processed through the state. We will make an attempt to indicate the fact that some contexts, in which "freedom to" takes place can incline us to accept the thesis that striving for materializing equality in it, in some circumstances, can result in reducing both positive and negative liberty, at least to some persons. However, it can have an impact not only in the field of economy or politics but also can have significant moral consequences.

\section{Negative and Positive Liberty}

Before we move on to main issues, we will focus our attention to present two types of individual liberty. The differentiation into positive and negative liberty is mostly related to the name of Isaiah Berlin [4]. In fact, this differentiation is older as it and originates from T. H. Green [14]. Negative liberty, which is also called "freedom from" is generally defined as the absence of external constraint or interference, whereas positive liberty (in other words "freedom to") is rather perceived as self-mastery or self-realization [15]. Negative liberty, in compliance with its name, is thus based 
on the lack of external (we can add unjustified) compulsion [18]. However, positive liberty is expressed in the possibility of action or also having the ability to do or possession of open options.

We can have the impression at first glance that negative liberty constitutes the basis of positive liberty that it is its necessary condition [19]. ${ }^{1}$ However, it is not this way. A basic phenomenon, around which the sense of a notion of negative liberty is established, is lack of. It is the lack of a compulsion, which is not justified by protecting against this constraint. Ability is such a phenomenon in the case of positive liberty. However, one is not a necessary condition of the other. The ability to do can be fulfilled irrespective of the fact, there is or there isn't external pressure placed on us. The absence of negative liberty does not mean the absence of ability at the same time and the lack of ability does not mean lack of negative liberty at the same time. In order to illustrate this statement, it is sufficient to indicate the fact that our possibility to vote for the parliament does not depend on the lack of external compulsion. "Freedom to" vote will be fulfilled in the equally good way in the case when we will not be forced by some external factor and also if we are pressured to vote by force or a threat of its use.

While negative liberty does not need material fulfillment to be processed, then positive liberty depends on possessed some kind of resources to some extent. It is not only dependent on a pay of a given person, however, we can also take it as gradable, because these persons, who dispose of greater resources, also have greater possibilities. Therefore, this means that they have a greater scope of positive liberty. Economic prosperity is an aspect of possessing resources, which is taken into account in the majority of cases. However, such approach has significant disadvantages. The term resources can be understood in many ways. It can be understood not only as a material pay of a given entity, but also physical, psychic or other properties, which decide about his or her possibilities [24, pp. 169-221].

When looking from this perspective, out of two persons of the same sex and age, the same health condition, the same height and the same physical fitness, this person who has greater knowledge, experience, intelligence or beauty, will have considerably greater capabilities than the other one. The problem will occur in the case when we will make an attempt to compare various categories, in which these properties occur. What does constitute greater capabilities of two comparable persons: advantage in the form of intelligence or beauty, admired features of character or extensiveness of knowledge? As long as comparable persons are not in a definite situation in a specific environment and saying in other words, do not find themselves in a definite context, their capabilities seem to be incomparable. Even so, as it could seem, a clear advantage, which is a higher level of prosperity of one person, can in some specific and extreme circumstances indicate a weakness rather than an ability. ${ }^{2}$ When drawing conclusions from this situation, we should refer to the notion of contextual capabilities or contextual advantage. When concluding this topic we can then say that positive liberty ( the ability of action) depends on the context of resources [1], ${ }^{3}$ which gain values due to a specific situation, in which a given entity is placed.

\section{Equality in Freedom}

The differences between both concepts of liberty in the perspective of our discussion, will be clearer when we compare them to the postulate of spread out equality in freedom [13, pp. 169-171], [9, p. 45-47]. ${ }^{4}$ Then it turns out that the consequences of making common liberty from compulsion will be different than popularising liberty as the ability to do. Fulfilment of the requirement of the lack of compulsion in the social sphere, will bring the same state of the lack of compulsion of each person in relation to all other persons [27], [17, p. 231]. The situation will look differently, if analogical actions will be concentrated on equalizing abilities to do. The cause of such a state of affairs is the fact that persons have been equipped with two possibilities with various level: ability to do or possession of open options. As we have mentioned earlier, these differences are in general based on disproportions in possessing properties, which are the source of the ability to do. The contrasts between persons can come from the differences in disposing of broadly understood 
resources, such as even: intelligence, talents, and features of character, physical fitness, skills and even beauty. Significant is not only the number of these properties, but also their indivisibility.

If a superior aim of action will be indicated as aspiration to equalize "freedom to", then we can imagine acting of a state, which will be directed to equalise these abilities to do by taking the capabilities away from these persons, who have more of them than the other ones and giving them to these, who do not have resources in such a way that abilities to do of everybody, resulting from the fact of possessing resources, will have a tendency to go in the direction of equality. The second manner of operating is processed by applying a derivative division of goods of economical character as an intention to change them for other capabilities, within the framework of the society treated as the whole. This solution is based, above all, on social redistribution of property, including primarily incomes. In this case, the declared aim is to: increase the level of abilities of these persons, who are in some way handicapped. In practice, it goes to transferring a part of goods that have been worked out or possessed by the society. However, in general, the mentioned goods do not constitute the property of the whole society, but they become it as a result of their appropriation. This process is conducted in the manner that some part of the possessed property is taken away from some categories of citizens defined by law, which will later supply completion of projects directed to support the ability to do of the other categories of persons. However, we should notice that the process of this type is based on using force in social life [26, pp. 89-115]. Therefore, it naturally seems to have an impact on the negative liberty of society members. Does it happen so in the real world?

We will make an attempt to visualize this problem by referring to the example, in which we will compare two different manners of transferring goods. We will use an example of donation here, which according to us provides important features of the whole problem. A voluntary donation will be the first one, whereas the second one will be a donation made under compulsion. On the basis of the analysis of these cases, we will make an attempt to define possible changes in the scope of liberty, which can take place in relation systems created in a donation process. If it turns out that there are differences in the scopes of liberty, the next step will be to try to compare a significance of both liberty types. In the further part we will try to interpret both of these situations in the perspective of their importance for the possibilities of fulfilling by persons their humanity. It will be, above all, an attempt to define, which influence of redistribution of properties is made on the ability of persons to initiate acts of moral nature.

\section{Thought Experiment of Donation}

A donation is a relation made between three types of entities: a donor, an agent and a donee. Before we start to make a more detailed analysis, we will refer to the status of entities before a donation. It is an initial situation, in which there are three entities that are not related to each other with any relation. We assume that each of them shall be entitled to the same negative liberty and some differentiated value (level) of positive liberty. A future donor disposes of "freedom to" with a higher level than a future donee. Disparities, which take place between them, in the level of this disposition are not significant, as the object of our interest will be the differences between an initial situation and a final one of individual entities.

A free donation is making a relation between entities and is based on the non-compulsory transfer of means by a donor, collected by an agent (for example a charity organization) [25], [20, pp. 393-394], which then disposes of it by supporting a donee. In the scheme of this relation, a donor is somebody who initiates action in this case. His act will be repeated by an agent. The situation is totally different in a case of compulsory donation. Three elements also take part in it, however, their mutual relations are different than the previous ones. The party which initiates an action is an agent in this case, which forces a donor to give away a part of possessed resources. Then it is passed to a recipient.

Let us try to interpret the aforementioned relations now in the light of a question about consequences, which are brought for the liberty of its members. We take a simplified assumption in 
this case and also in the whole work that the transferred goods are freely exchanged for capabilities and the last ones reflect the scope of positive liberty. The first point of reference will be the initial situation before a donation. When looking for the whole idea from the perspective of liberty, the final result shows extensive changes in relation to the initial point.

In conditions of voluntary donation, a donor has resigned from a part of his abilities (and despite this fact and maybe thanks to it, he fulfilled his positive liberty) and strengthened this type of liberty in a donee. A donee has had his positive freedom expanded. Moreover, an agent has received, in relation to a status, which has been before a donation, an additional aspect of positive liberty that is based on the ability to transfer means from a donor to a donee. Let us also notice at the same time that none of the entities has sustained a loss in the field of negative liberty, which he or she is entitled to. However, if we take into account compulsory donation, the situation will look otherwise.

Positive freedom of a donee has been increased in this situation in relation to the original one, whereas its level has been decreased in the case of a donor. Therefore, it seems that there are no differences in relation to the characteristics of voluntary donation in this respect. However, a change has taken place here and it is of vital importance. While in the case of a voluntary donation a donor fulfils his or her positive liberty, they use it in some sense, by decreasing their possibilities by such action (we use money for the same purpose by spending them, which does not mean that we lose it, as we simply change it and materialise its value), so the same possibilities are taken away from a donor in the case of a compulsory donation. He does not show his abilities in this case. He does not do this, which expresses his will, but acts in a way that is in compliance with the will of the other people. In the case of an agent, a change has taken place in relation to a state before a donation and towards a voluntary donation. It has revealed an additional scope of positive liberty, which is based on the possibility to transfer means from a donor to a donee, but also the ability to force a definite action on a donor, which has not seen before. This special ability to force actions on other entities is called power in other words ${ }^{5}$. It means that an agent has power over a donor.

As regards the scope of negative liberty, we need to acknowledge that its scope in a donor has been limited both in relation to the original situation and also in comparison to a voluntary donation. The other entities, which participate in a relation, will not record any changes in this respect.

When we look at relations between entities as a certain closed system, then we can attempt to evaluate an increase and decrease of both types of liberty in the perspective of the whole. Thus, the whole system before a donation has been in a state, which has later changes together with donations. A voluntary donation has resulted in passing an aspect of positive freedom to a donee. It has co-existed with its fulfillment in a donor at the same time. As we have already indicated, such materialization is not identical to a loss, but rather an exchange. The scope of this type of liberty in an agent has increased in the same way. As a result, our interpretation goes in the direction of an ascertainment that a voluntary donation has caused an increase of a positive liberty in the whole system, with maintaining the same status of negative liberty.

The consequences of a compulsory donation seem to be significantly different. A transfer of positive liberty from a donor to a donee has taken place within the framework of the system, in which it has been taken from a donor, but not fulfilled at the same time. Moreover, an agent has gained one more ability - power - in comparison to a voluntary donation. In conclusion, negative liberty had decreased for the whole relation system with reference to the state from before a donation but positive liberty increased. However, the level of the last one has increased as a result of the transfer between a donor and a donee, as a part, which has been taken away from a donor, has been given to a done, ${ }^{6}$ therefore, its value has remained the same for the whole system. The status of positive freedom has increased in the system by making a relation of an agent who has power over a donor. Therefore, an occurrence of a phenomenon of power is an additional aspect of positive freedom in this case. However, the scale of negative liberty has decreased for the whole system in compulsory donation in relation to voluntary donation, whereas positive liberty has 
remained at the same level (adding the ability to do in the form of power of an agent has been balanced by a loss of ability to do of a donor as a result of its fulfilment).

\section{Consequences of Equal Liberties}

In the case of equalizing differences in "freedom to" that is implementing the procedure of equalizing abilities to do in society in practice, it should be expected that the maximum positive liberty of some entities, coming from the fact of possessing capabilities by them, will be considerably reduced. A transfer of resources could not otherwise take place, which increases a status of positive liberty of other entities that have less. Such actions will definitely have an impact on the negative liberty of an entity which has the greatest capabilities. Then it will have to lead to the annihilation of the postulate of equal "freedom from". Therefore, it seems that equality in negative liberty and aiming to equalize positive liberty cannot be reconciled. William Dustin claims, that clashes between representatives of these views ,represent not conflicts of style, but vastly different moral orders" [10, p. 33]. One of these postulates must give place to the other one.

In the light of the aforementioned information, we still can attempt to answer a question related to the significance of both postulates. Which one of them is more important and/or consequences of which one of these solutions we are more inclined to accept. The case of compulsory donation, which has been described above, has shown how a transfer of liberty looks like within the framework of the whole relation system. The increase of positive liberty has finally taken place there, as well as the decrease of negative liberty compared to the status from before a donation, the decrease of negative liberty and the lack of a change in the scope of positive liberty with reference to voluntary donation. Therefore, it is would be worth to consider, if the increase of "freedom to" compensates, for the whole system, the decrease of the level of "freedom from". The answer to this theoretical question would help us understand the significance of both types of freedom in real social life.

\section{Imaginary Situation of Competition}

If we would like to consider this problem, then we can refer to an imaginary situation again. Let us rethink, which equality in liberty we should value more and which one we can sacrifice, if it is not possible to combine both of them. In order to study this problem, we will concentrate on the situation, in which we assume the same context of capabilities for two entities $(A$ and $B)$ as well as different level of them ceteris paribus.

1. In the first case, both entities are equally independent of an external unjustified compulsion. The entity $A$ possesses considerably greater capabilities than the entity $B$. Therefore, $A$ disposes of bigger possibilities, so it has greater positive liberty than $B$ has.

2. In the second example $A$ and $B$ dispose of equal scopes of positive liberty (they have the same capabilities), however, $B$ possesses a considerable advantage in the scope of negative liberty. It means that $A$ is not only under greater risk of external unjustified compulsion (unjustified protection from a compulsion), but is also subject to an external limiting compulsion to a greater extent than $B$ is.

3. The last example presents a situation, in which $A$ has greater positive liberty (disposes of greater capabilities) than $B$ and is at the same time hindered towards the other one in the scope of negative liberty. $A$ has less negative freedom than $B$.

Now we will consider three aforementioned cases for two circumstances. Firstly, the relation of competition between entities - zero-sum interaction; secondly, for the relation characterized by the lack of competition between entities - non-zero-sum interaction. We will understand the zerosum interaction in a special manner here, namely that two entities in a mutual relation cannot win at the same time. If one of them wins, then the other one needs to lose. In contrast to this situation, the non-zero-sum interaction (in this specific case, we take into account a positive-sum), which will be defined here as the one, in which each party (at least subjectively) acknowledges that the party has 
gained more on the transaction than lost from it. ${ }^{7}$ Let us make an attempt a situation by placing it in a field of economy. Two competing sellers or two competing buyers will take part in the first relation. The second relation describes the occurrence, which will happen between a seller and a buyer. example.

Competition - interaction with zero-sum. ${ }^{8}$ The situation of an auction will be taken as an

Re 1 . The buyer $A$ has greater abilities (more money) than buyer $B$. The external conditions for both of them are the same, then we should expect that $A$ will win.

Re 2. Both buyers have the same abilities (the same amount of money), but $A$ can be excluded from the auction, for example by intimidation or implementing a ban for participating in the auction for some categories of buyers. Therefore, $A$ is subject to discrimination. $B$ will win.

Re 3. The buyer $A$ has greater possibilities than $B$, but can also be excluded from participating in the auction ( $A$ is subject to discrimination). Therefore $B$ will win again.

The case no. 1 is most similar to sport situations. Despite the lack of equality in positive liberty, the equality in negative liberty (the same rules for all participants) results in the situation that a victory seems to be honest. The cases 2 and 3 confirm the situation, which has been earlier indicated by an example of compulsory donation. Despite the fact of possessing capabilities in theory, fulfillment of positive liberty does not take place due to interference in the independence of an entity (decreasing the scope of negative liberty). Therefore, depreciation of negative liberty can also result in reducing the positive liberty of these entities, for which negative liberty has not been infringed. Negative liberty in entity $A$ has been reduced in both of these cases, which has also become a barrier for fulfilling its positive liberty.

No competition - interaction with non-zero-sum. We will consider a relation of a seller - a buyer in this case. ${ }^{9}$

Re 1 . The seller $A$ that possesses more capabilities, proposes his product $x$ to the buyer $B$. The last one is neither forced to its purchase nor is it made impossible for him.

$\operatorname{Re} 2$. Two possibilities are differentiated in this case:

a) The seller is $A$ that has the same resources as $B$, yet is subject to external compulsion to sell $x$, for example at a reduced price;

b) The seller is $B$ that has the same resources as $A$, yet can be forced to buy $x$ at a higher price or to buy it in general, for example as an indispensable element of equipment of the product $y$ offered by $B$.

Re 3. The same case as the previous one:

a) The seller $A$, despite the fact of possessing greater capabilities than the buyer $B$, is forced to sell $x$ to $B$ at a lower price;

b) The buyer $A$, despite the fact of possessing greater resources than the buyer $B$, is forced to buy $x$ at a higher price.

The relations reviewed here also show that until positive liberty of some does not have an impact on the negative liberty of the other ones. The relations seem to be honest, despite the fact of a difference in capabilities. The next cases in the example of interactions with non-zero-sum value show something else. The first case (of equality in negative freedom) remains an interaction of positive sum. Both parties of the relation have an open way to fulfill positive liberty, which has been granted to them, while maintaining negative liberty at the same time. The other cases fall into the category of interactions with zero-sum, in which one party must lose, so that the other one can win.

However, the provided examples raise a significant doubt. Does inequality of capabilities (positive liberty) really lead to fair competition? The example of sport, in which abilities of competitors almost always are unequal seems to indicate the affirmative answer to this question should. Our analysis is made difficult by the fact that real equality of capabilities in conditions of functioning of the society seems not only to be incomparable, but also unachievable. As we have already highlighted, equality of capabilities can only be contextual. However, persons are found in this meaning in various contexts at the same time. 
Now back to the considered postulate of equal positive liberty. It seems that it should be acknowledged one important aspect. Even if we set a goal to lead to equalize everyone in an arbitrarily selected context, then we should still expect that we will be able to achieve it at the price of actual discrimination of at least some persons. When we write about postulates of equality in positive liberty, which exclude each other, we should also add some more information here. Thus, the postulate of equal positive liberty can have an impact on equal negative liberty. In contrast, the postulate of negative liberty does not infringe positive liberty. The requirement of common equalizing of the state of lack of compulsion does not change and therefore, does not infringe capabilities of anyone.

\section{Conclusion}

What is the significance of the aforementioned deliberations related to donations and the importance of both types of liberty to justify the postulate of popularising equality in positive liberty? Such postulate in politics of many contemporary countries is fulfilled in the form of social redistribution of resources. It seems to be analogical to a situation of compulsory donation, which has been presented here. However, if such a situation takes place, its consequences for freedom of both types should be taken into account. The topic of the greatest interest for us is not a political but ethical aspect of the problem. The problem of moral aspects of redistribution can be important for that as human beings are treated.

It is commonly acknowledged and probably justifiable that out of all known creatures, a human is somebody special. ${ }^{10} \mathrm{We}$ name the others, who are similar to us as someone, and not something. Why is that? Various answers were provided to this question. We will refer in this case to some remark of Aristotle that a property that differentiates a human is his ability to discern good from evil and justice from injustice [2]. Not the ability to discern itself and to think in moral categories seems to be the only important one. It is also the fact that people have the ability to act in a moral manner. Persons are active entities, who discern just from unjust acting and can knowingly behave in a just or unjust manner. Therefore, the most significant factor seems to be the ability to make a choice in the light of possible options. ${ }^{11}$

Immanuel Kant pays attention to this property in Groundwork of the Metaphysics of Morals by making freedom as the condition of morality in general [16]. The freedom that Kant talks about, is understood as the possibility of acting in this or another way. When looking from our perspective, we should interpret it as positive freedom. This freedom is nothing else but an ability to act. The perfect condition for the fulfillment of the fullness of humanity would be the state of the greatest possible freedom of making decisions for all persons. It would be such a state, in which people will not necessarily make the greatest consequence of actions, but it would be the state, in which acting would be the most related to the notion of the moral duty. It means that the greatest possible number of acts would depend on free decisions of individual persons.

It is natural that the situation, in which there would be the maximum scale of acting of persons that discern good from evil and justice from injustice does not necessarily mean that these persons would prefer good and just actions as well as that they would select these acts which refer to them. According to Nozick, it doesn't mean yet that the state should violate human freedom: "The state may not use its coercive apparatus for the purpose of getting some citizens to aid others" $[23$, p. ix]. What would in such a case constitute a barrier preventing from bad and unjust actions of maximally free persons? The answer in this case of justice is certainly securing the maximum negative liberty and the greatest possible level of equality in it. Then we will have two different states in this case. Firstly, with maximum freedom and secondly with equal freedom. We should highlight their difference here. The maximum negative liberty in real social conditions is such a situation of a given entity, in which this entity is hampered with limitation to the lowest extent. However, equal negative freedom is characterized by the same scope of limitations for everybody. It neither limits nor has an impact on a change of a positive freedom status. 
We should pay attention to a paradox of positive liberty. Both, the greatest positive liberty and also equal positive liberty are obtained as a result of actions, of which, depreciation of negative liberty can be expected, at least in some entities. The postulate of equalizing of positive liberty can also lead to a situation which can be evaluated as morally destructive. Considering a compulsory donation, it firstly can lead to limiting the ability to act in a moral way by these persons, whose property has been taken away. Secondly, we should place a donee in a situation that is morally ambiguous, as he profits from taking away of someone's property. The situation of a donee seems to be similar to a situation of a person, who has received a present coming from a theft. Finally and thirdly, an agent becomes a person who deprives persons of their moral subjectivity as he treats them as objects, means that are used to achieve his own aims.

In this text we have basically concentrated on some consequences of the postulate of equal freedom. This proposal refers to property redistribution in practice. Therefore, we cannot avoid a question related to an admissible scope of this redistribution. As it seems, the conclusions resulting from the presented examples should incline us to approve the thesis that a redistribution, which aims at equalizing scopes of positive liberty has its not extendible limit. It is a violation of equal negative liberty of entities that are full society members. ${ }^{12}$ Thus, each it's exceeding results in reducing the independence of persons. However, it turns out that it can lead to reducing their real abilities. Therefore, fulfillment of the postulate of equal abilities can have an impact not only on freedom from compulsion, but also in fulfillment of positive liberty in some persons. What is more, some forms "freedom for" can generate occurrence and increase of power relations.

Apart from losing currently possessed possibilities and liberties by some persons, another consequence can also occur in the form of limiting their properties as a moral creature. As they have been deprived of a part of their current negative and positive liberty, which they have been entitled to earlier and as a result they have also been limited in their moral duties that are contingent upon these liberties. Their moral autonomy for this reason depreciate. However, this can result in the reification of these persons. As a consequence, it can happen that they will be reduced from the level of somebody to something. The history tells us that depriving selected groups their autonomy, has born the bitterest fruits. Therefore, it seems that the postulates the implementation of equality in positive liberty coerced by state institutions, should be treated with restraint and with special prudence.

\section{References}

1. Alexander, J. M. Capabilities and Social Justice: The Political Philosophy of Amartya Sen and Martha Nussbaum, Aldershot: Ashgate Publishing, 2008.

2. Aristotle. The Politics, Indianapolis: Hackett Publishing, 1998.

3. Ayau, M. F. Property Rights and the General Theory of Exchange: Frequently Neglected Implications of the Division of Labour and the Law of Comparative Advantage, Economic Affairs, 26. No. 1, 2006, pp. 48-53.

4. Berlin, I. Two Concepts of Liberty, In Four Essays on Liberty, Oxford: Oxford University Press, 1969.

5. Boethius. Theological Tractates, London: Heinemann, 1973.

6. Brenkert, G. G. Political Freedom, London: Routledge, 2006.

7. Ciulla, J. B. Worthy work and Bowie's Kantian theory of meaningful work. In D. G. Arnold \& J. D. Harris (eds.), Kantian Business Ethics: Critical Perspectives, Northhampton: Edward Elgar Publishing, 2012.

8. Darwall, S. L. (ed.). Equal Freedom: Selected Tanner Lectures on Human Values, Ann Arbor: University of Michigan Press, 1995.

9. Denier, Y. Efficiency, Justice and Care: Philosophical Reflections on Scarcity in Health Care, Dordrecht: Springer Science \& Business Media, 2007.

10. Dustin, W. Toward an Ethic of Citizenship: Creating a Culture of Democracy for the 21st Century, New York: toExel Press, 2000. 
11. Epstein, R. A. The Rise of Transfer Payments. In G. C. Bryner \& N. B. Reynolds (eds.), Constitutionalism and Rights, Provo: Brigham Young University Press, 1987.

12. Gołaszewska, M. Roman Ingarden's Moral Philosophy. In A. Tymieniecka (ed.), Ingardeniana, Dordrecht: Reidel, 1976.

13. Gould, C. C. Rethinking Democracy: Freedom and Social Co-operation in Politics, Economy, and Society, Cambridge: Cambridge University Press, 1990.

14. Green, T. H. Liberal Legislation and Freedom of Contract. In R. L. Nettleship (ed.), Works of Thomas Hill Green, vol. 3, London: Longmans Green, 1991.

15. Hayek, F. A. von. The Constitution of Liberty, London: Routledge, 1960.

16. Kant, I. Practical Philosophy, M. J. Gregor (ed. and trans.), Cambridge: Cambridge University Press, 1996.

17. Kant, I. The Metaphysics of Morals, Cambridge: Cambridge University Press, 1991.

18. Locke J. Two Treatises on Government, P. Abrams (ed.), Cambridge: Cambridge University Press, 1967.

19. MacCallum, G. C. Jr. Negative and Positive Freedom, Philosophical Review 76, 1967, 312-344. 20. Macey, J. R. On the Failure of Libertarianism to Capture the Popular Imagination. In E. Frankel Paul, F. D. Miller, \& J. Paul (eds.), Problems of Market Liberalism: Volume 15, Social Philosophy and Policy, Cambridge: Cambridge University Press, 1998.

21. Narveson, J. Respecting Persons in Theory and Practice, Boston: Rowman and Littlefield, 2002.

22. Nolan, P. Capitalism and Freedom: The Contradictory Character of Globalization, London: Anthem Press, 2007.

23. Nozick, R. Anarchy, State, and Utopia, New York: Basic Books, 1974.

24. Sen, A. Well-being, Agency and Freedom. Journal of Philosophy 82. No 4, 1985, 169-221.

25. Tanner, M. The End of Welfare: Fighting Poverty in the Civil Society, Washington: Cato Institute, 1996.

26. Vaubel, R. Socialism. Do the Ends Justify the Means. In S. Pejovich (ed.), Socialism: Institutional, Philosophical and Economic Issues, Dordrecht: Springer Science \& Business Media, 2012.

27. Weinstein, D. Equal Freedom and Utility: Herbert Spencer's Liberal Utilitarianism, Cambridge: Cambridge University Press, 2006.

28. Wright, R. Nonzero: History, Evolution \& Human Cooperation, London: Abacus, 2001.

\section{Notes}

1. For example, MacCallum assumes that the two kinds of the freedom are indivisible elements of one liberty, and the dichotomy of them is false [19, pp. 312-334].

2. It is sufficient to imagine two men in the prime of their life: a wealthy and a poor one, which have found themselves in the storm of the bolshevik revolution in Russia to realize relativity the notion of greater capabilities. As in this case and this context, greater material resources of the first person, make his situation worse at the same time, in which he is under a threat of persecution from the others, who would like to make a new order.

3. About connections between freedom, resources and abilities [6, pp. 236-242].

4. Wider scope of equal liberty form different points of view see [8].

5. Richard Epstein compare government holding this kind of power to Robin Hood "taking from the rich and giving to the poor. No one disputes that individuals are entitled to make voluntary charitable contributions. But it is a different matter when some people try to fund their gifts with cash taken from their neighbor's pockets" [11, p. 34].

6. The natural evaluation of the ability to do depends on a broader context. A significant impact on it will undoubtedly have the level of usability of transferred capabilities, which will be greater if the capabilities of a donee are smaller, whereas it will be lower if capabilities of a donor are greater.

7. About positive sum in economy see: [6].

8. In this issue see: [28], [22, pp. 55-56].

9. Some theorists hold different views on this matter. For example Joanne B. Ciulla considers relations between a seller and buyer (in her case employer and employee) in terms of zero-sum game [7, p. 124]. 
10. Long time the basic notion in this respect referred to the Boethius definition: „The person is an individual substance of rational nature" [5, pp. 84-85].

11. Maria Gołaszewska adduces on the matter to Roman Ingraden's opinion. A man losses his freedom "when he becomes like a mechanism surrendering to command of the moment, when he himself is not the source of his decisions" [12, pp. 73-104].

12. For instance inviolability of negative freedom can be limited by common consent for the actions that rely on redistribution of goods, see: [21]. 